\title{
Alcohol Consumption in Russia and Some Aspects of Public Health
}

\author{
Sergei Jargin ${ }^{1, *}$ \\ ${ }^{1}$ Department of Public Health, Peoples' Friendship University of Russia, Moscow, Russia \\ *Corresponding author: Sergei Jargin, Department of Public Health, Peoples' Friendship University of Russia, Climentovski Per 6-82; 115184, Moscow, Russia. Tel: +7-4959516788, Fax: \\ +7-4959516788, E-mail: sjargin@mail.ru
}

Received 2015 January 7; Revised 2015 February 21; Accepted 2015 February 23.

\begin{abstract}
Context: The problem of alcohol misuse in Russia is immense; but nonetheless there is a tendency to exaggerate it, which is evident for inside observers. Such exaggeration tends to veil shortcomings of the health care system with responsibility shifted onto the patients, that is, self-inflicted diseases caused by excessive alcohol consumption. The aim of this report is to draw attention to the above-mentioned and other problems related to the alcohol consumption in Russia, not clearly perceptible from the literature, e.g. toxicity of some legally sold alcoholic beverages.

Evidence Acquisition: This report is based on a review of literature and observations by the author during the period 1970 - 2014.

Results: Predictable increase of alcohol consumption after the anti-alcohol campaign facilitated the economical reforms of the early $1990 \mathrm{~s}$ : workers and some intelligentsia did not oppose privatizations of state-owned enterprises partly due to their drunkenness, involvement in workplace theft and use of equipment for profit, which was often tolerated by the management at that and earlier time.

Conclusions: Last time, a gradual change of the alcohol consumption pattern in Russia has been noticed: less heavy binge drinking of vodka, fortified wine and surrogates; more moderate consumption of beer.
\end{abstract}

Keywords: Alcoholism, Russia, Alcoholic Beverages, Health Care Quality, Access, Evaluation

\section{Context}

The problem of alcohol misuse in Russia is immense; but nonetheless there is a tendency to exaggerate it, which is evident for inside observers. Such exaggeration tends to veil shortcomings of the health care system, with responsibility for the relatively low life expectancy shifted onto the patients, that is, supposedly self-inflicted diseases caused by excessive alcohol consumption. During the anti-alcohol campaign (1985 - 88), a widespread consumption of non-beverage alcohol was observed: perfumery and technical fluids such as window-cleaner, which caused up to severe intoxications. Considering the large scale of the window cleaner sales in some places e.g. in Siberia, it was knowingly tolerated by authorities. The alcohol consumption predictably increased after the anti-alcohol campaign. Following the abolition of the state alcohol monopoly in 1992, the country was flooded by legally sold alcohol of poor quality (1); more details are in $(2,3)$. It was reported that about a half of the cases of lethal intoxication by alcohol-containing fluids during the 1990s were caused in some areas by legally sold beverages, while in many lethal cases a relatively low blood alcohol concentration was detected (4).

The aim of this report was to draw attention to the problems related to the alcohol consumption in Russia: indirect misplacement of responsibility for the relatively low life expectancy and high mortality onto the patients, who supposedly suffered from self-inflicted diseases caused by excessive alcohol consumption; instable quality and toxicity of some legally sold alcoholic beverages, which have sometimes caused poisonings even after consumption in moderate doses; offences and crime against alcoholics and people with alcohol-related dementia, sometimes aimed at appropriation of their apartments, houses and other property; violation of their human rights and humiliating treatment by some employers and civil servants.

\section{Evidence Acquisition}

Apart from a review of the literature, this report has been based on the observations by the author, who entered the I.M. Sechenov medical academy (named Institute at that time) in the year 1973, later practiced at the same and other academic and clinical institutions in Moscow. The time of observation of the alcohol-consuming milieu included the period 1970 - 2014.

\section{Results}

The trends for life expectancy have improved in many areas of the world. However, those in Russia have not

Copyright (C) 2016, Zahedan University of Medical Sciences. This is an open-access article distributed under the terms of the Creative Commons Attribution-NonCommercial 4.0 International License (http://creativecommons.org/licenses/by-nc/4.0/) which permits copy and redistribute the material just in noncommercial usages, provided the original work is properly cited. 
shown any significant growth since the middle of the 20 th century (5). In the author's opinion, one of the reasons has been stagnation in the field of health care (6). In the early 1990s, the health care system in Russia was partly disorganized. At the same time, the average life expectancy at birth decreased considerably, especially in men: by 1993 it had slumped to about 59 years (7). Medication costs for outpatient treatment are not covered by the compulsory medical insurance in Russia. Modern therapy of chronic diseases such as hypertension and diabetes mellitus is hardly available on a regular basis for many people. Irregular treatment of hypertension is now as before a problem in the former SU (8), obviously contributing to the higher cardio- and cerebrovascular mortality.

There are indications that the cause-effect relationship between the alcohol consumption, cardio- and cerebrovascular mortality e.g. in (9-14) was exaggerated. At the same time, the mortality from cardio- and cerebrovascular diseases has obviously been overestimated (6). According to the author's observations during the 1980 - 90s, cardiovascular diseases were often overdiagnosed post mortem in unclear cases. After 1990 the quality control in pathology deteriorated; autopsies were sometimes performed perfunctorily. If a cause of death was unclear, it has often been written on death certificates: "Ischemic heart disease with cardiac insufficiency" or a similar formulation. A tendency of false-positive post mortem diagnosis of cardiovascular diseases existed also for people dying at home without autopsy. Stroke as a cause of death has sometimes been diagnosed in patients with neurological symptoms, which in reality could have been caused by intoxication with substances other than ethanol. Quality decrease in pathology and in the health care in general during the 1990s coincided with the increase in cardiovascular mortality $(5,10)$; at the same time, the stroke mortality "jumped dramatically" (9). Overdiagnosis coupled with insufficient medical attention is obviously an important cause of the increase in the registered cardio- and cerebrovascular mortality. The alcohol consumption, increased after the anti-alcohol campaign, certainly contributed to the enhanced mortality. However, exaggeration of the causative role of alcohol befogs other preventable causes of the higher mortality. Statements like "alcohol accounts for most of the large fluctuations in Russian mortality, and alcohol and tobacco account for the large difference in adult mortality between Russia and western Europe" (12) veil another cause of the difference: insufficient availability and quality of health care.

The following citation is illuminative in this connection: "Increases and decreases in mortality (have been) related to cardiovascular diseases (CVD), particularly to 'other forms of acute and chronic ischemia' and 'atherosclerotic heart disease', but not to myocardial infarction, the proportion of which in Russian CVD-related mortality is extremely low" (11). The reason is evident: the diagnosis of myocardial infarction is usually made on the ba- sis of clear clinical and/or pathological criteria, whereas "atherosclerotic heart disease" has often been diagnosed post mortem unsupported by evidence. On the contrary to myocardial infarction, gross features of a cerebral infarction can be imitated destroying brain tissue e.g. by a junior pathologist or postgraduate student not inclined or unable (due to unavailability of toxicological tests etc.) to search for a cause of death. There were cases of falsepositive post mortem diagnosis of cerebral infarctions at an academic institution, which has probably happened more frequently in hospitals with no supervision over the quality of post mortem examinations.

Furthermore, the term alcoholic cardiomyopathy was sometimes used post mortem without sufficient evidence. In a large autopsy study, all 654 deceased "alcohol abusers" were diagnosed with cardiomyopathy predominantly of moderate degree; while in the majority of alcoholics (registered as such with substance abuse prevention and treatment centers) (172 cases) the cardiomyopathy was graded as pronounced (14). According to a study (13), clinically significant cardiomyopathy had been diagnosed in approximately $50 \%$ of habitual drinkers consuming in equivalent $60-80 \mathrm{~mL}$ pure alcohol/day or more. Cause and effect of the alcohol misuse are sometimes mixed up: for example, the images of malformations of teeth or feet are presented as manifestations or sequels of alcoholism (13); in fact, however, people with curable malformations, often remaining without help in Russia, can be psychologically predisposed to alcoholism. Cardiomyopathy was claimed to be a frequent cause of sudden death of alcoholics (14), which in some cases could have been caused by undiagnosed and untreated diseases, intoxications etc. The tendency to exaggerate the cause-effect relationship between alcohol and the cardiovascular morbidity/mortality is relatively new in Russia. An earlier epidemiological study reported that the rates of cardiovascular diseases including hypertension were not significantly higher among excessively drinking men compared to the male population in general (15).

The curves of alcohol consumption and stroke mortality follow each other (9); but the estimation method of alcohol consumption is questionable: "The harm indicator series used was alcohol psychosis incidence rate because this indicator depends almost entirely on alcohol consumption" (9). The incidence of alcohol psychoses may reflect the alcohol consumption in the countries with a stable quality of alcoholic beverages but not in Russia, where the quality of legally sold alcohol worsened during and especially after the anti-alcohol campaign. It would be reasonable to assume that psychosis-like conditions can be induced not only by ethanol but also by other substances in poor-quality alcoholic beverages. We observed marked mental confusion after a moderate consumption of fortified wines purchased in shops.

Discussing alcohol-related diseases, acute pancreatitis should also be mentioned. Epidemiologic data indicate 
a higher frequency of alcohol-induced acute pancreatitis in geographical areas where surrogates or homemade alcoholic beverages are easily available (16). Such beverages contain, in addition to ethanol, considerable admixtures of higher alcohols (e.g. propanol and butanol) and other contaminants (aldehydes, esters etc.), whose potency to induce pancreatic damage is insufficiently known (16). The main conclusion of the article (17) is that "unfavorable mixture of higher overall level of alcohol consumption and binge drinking pattern is an important contributor to the pancreatitis mortality rate in Russian federation." This is obviously true; however, as discussed here in the next paragraph, the overall alcohol consumption in Russia tends to decrease, and the heavy binge drinking pattern is visibly in decline. Poor quality of alcoholic beverages should be pointed out among preventable causes of the relatively high frequency of acute pancreatitis in Russia (17).

Exaggeration of the problem of heavy binge drinking tends to misplace responsibility for the health-related risks onto the drinkers, supposed to choose this risky pattern of alcohol consumption. According to Razvodovsky (9), "Epidemiological evidence suggests that binge drinking is an important determinant of high stroke mortality rate in Russia”. It should be commented that heavy binge drinking has been visibly decreasing since approximately the year 2000 or even earlier time, especially in large cities. During the Soviet time and shortly thereafter, many heavily drunk individuals could be observed in the streets, public gardens, long-distance trains etc. Today, there are not so many drunks even among marginalized people. Along with the changing pattern, there is a general tendency of alcohol consumption decrease since approximately the last decade (18); for an observer this tendency appears to be marked. Wine and vodka have been partly replaced by beer (18), which has also contributed to a decline in the heavy binge drinking pattern. Many young people drink today one to several cans of beer during an evening but not a bottle of vodka with beer for three or two persons, as it used to be during the 1970 - 80 s. Fortified wines or their imitations (containing 17-20\% of alcohol) were also massively consumed during the 1970 80 s, while a 0.75 liter bottle per person was a usual dose; more details are in (3). The causes of the gradual change of the drinking habits have been discussed previously: more responsible way of life under the market economy, intimidation and crime against alcoholics and people with alcohol-related dementia, aimed at appropriation of their apartments, houses or other property $(3,19)$.

Furthermore, in some papers on consumption of nonbeverage alcohol (20), the readers' attention is diverted to technical fluids (household chemicals, disinfectants, window-cleaners) and moonshine (samogon). It should be commented that the relative price of vodka/average salary was approximately 5 times higher in 1985 prior to the anti-alcohol campaign compared to the year 2010 (3). High consumption of non-beverage alcohol would be improbable in conditions of low prices for legally sold alcoholic beverages and their easy availability. It is in accordance with the author's observations that consumption of alcohol-containing technical fluids, lotions etc. decreased abruptly after the anti-alcohol campaign. There are obvious motives to exaggerate the consumption of non-beverage alcohol: to disguise the issue of toxicity of some legally sold alcoholic products.

\section{Conclusions}

The predictable increase in alcohol consumption after the anti-alcohol campaign obviously facilitated the economical reforms i.e. privatization of the state-owned enterprises during the 1990s. Workers and some intelligentsia did not oppose privatizations of governmental enterprises, occurring not always in accordance with the law, due to their drunkenness, involvement in workplace theft, use of equipment and consumables for profit, theft of technical or medicinal alcohol etc., which was tolerated by the management. The management themselves were known and seen to purloin alcohol in scientific and medical institutions. Furthermore, there has been a stereotype, partly preserved from the Soviet time: post-graduate students and doctoral candidates came to Moscow and other centers from different parts of the country. Some of them have been prepared to pay for literature reviews, preparation of specimens, etc. Certain doctors planning emigration accomplished their dissertations under time pressure. Among others, invasive methods such as endoscopy, organ biopsy or surgical operations were applied without sufficient clinical indications sometimes in conditions of suboptimal procedural quality assurance. This kind of research involved also alcohol abusers (21-23). In conclusion, a society should care for its vulnerable members, including aged citizens suffering of alcoholism and alcoholrelated dementia.

\section{References}

1. Razvodovsky YE. Affordability of alcohol and alcohol-related mortality in Belarus. Adicciones. 2013;25(2):156-62. [PubMed: 23748944]

2. Jargin SV. Alcohol consumption by Russian workers before and during the economical reforms of the 1990s. Int J High Risk Behav Addict. 2013;2(2):48-50. doi: 10.5812/ijhrba.11004. [PubMed: 24971274]

3. Jargin SV. Letter from Russia: minimal price for vodka established in Russia from 1 January 2010. Alcohol Alcohol. 2010;45(6):586-8. doi:10.1093/alcalc/agq061. [PubMed: 20935074]

4. Nuzhnyi VP, Kharchenko VI, Akopian AS. [Alcohol abuse in Russia is an essential risk factor of cardiovascular diseases development and high population mortality (review)]. Ter Arkh. 1998;70(10):57-64. [PubMed: 9864807]

5. Zatonski WA, Bhala N. Changing trends of diseases in Eastern Europe: closing the gap. Public Health. 2012;126(3):248-52. doi: 10.1016/j.puhe.2011.11.017. [PubMed:22325674]

6. Jargin SV. Health care and life expectancy: a letter from Russia. Public Health. 2013;127(2):189-90. doi: 10.1016/j.puhe.2012.11.003. [PubMed: 23200435]

7. Ryan M. Alcoholism and rising mortality in the Russian Federation. BMJ. 1995;310(6980):646-8. [PubMed: 7703754]

8. Roberts B, Stickley A, Balabanova D, Haerpfer C, McKee M. The 
persistence of irregular treatment of hypertension in the former Soviet Union. J Epidemiol Community Health. 2012;66(11):1079-82. doi:10.1136/jech-2011-200645. [PubMed: 22447959]

9. Razvodovsky YE. Fraction of stroke mortality attributable to alcohol consumption in Russia. Adicciones. 2014;26(2):126-33. [PubMed: 25225729]

10. Razvodovsky YE. Contribution of alcohol to hypertension mortality in Russia. J Addict. 2014;2014:483910. doi:10.1155/2014/483910. [PubMed: 24829843]

11. Davydov MI, Zaridze DG, Lazarev AF, Maksimovich DM, Igitov VI Boroda AM, et al. [Analysis of mortality in Russian population]. Vestn Ross Akad Med Nauk. 2007;(7):17-27. [PubMed:17718076]

12. Zaridze D, Brennan P, Boreham J, Boroda A, Karpov R, Lazarev A, et al. Alcohol and cause-specific mortality in Russia: a retrospective case-control study of 48,557 adult deaths. Lancet. 2009;373(9682):2201-14. doi: 10.1016/S0140-6736(09)61034-5. [PubMed: 19560602]

13. Vertkin AL, Zairat'iants OV, Vovk EI. Moscow: Geotar-Media [in Russian]; Final diagnosis, 2009.

14. Paukov VS, Erokhin Iu A. [Pathologic anatomy of hard drinking and alcoholism]. Arkh Patol. 2004;66(4):3-9. [PubMed: 15449679]

15. Kopyt N, Gudzhabidze VV. [Effect of alcohol abuse on the health indices of the population]. Zdravookhr Ross Fed. 1977;(6):25-8. [PubMed: 883432]

16. Barreto SG, Saccone GT. Alcohol-induced acute pancreatitis: the 'critical mass' concept. Med Hypotheses. 2010;75(1):73-6. doi: 10.1016/j.mehy.2010.01.036. [PubMed: 20181433]

17. Razvodovsky YE. Alcohol consumption and pancreatitis mortality in Russia. JOP. 2014;15(4):365-70. doi: 10.6092/1590-8577/2273. [PubMed: 25076345]

18. Neufeld M, Rehm J. Alcohol consumption and mortality in Russia since 2000: are there any changes following the alcohol policy changes starting in 2006? Alcohol Alcohol. 2013;48(2):222-30. doi:10.1093/alcalc/ags134. [PubMed: 23299570]

19. Jargin SV. Elder abuse and neglect versus parricide. Int J High Risk Behav Addict. 2013;2(3):136-8. doi: 10.5812/ijhrba.14983. [PubMed: 24971292]

20. Razvodovsky YE. Consumption of Noncommercial Alcohol among Alcohol-Dependent Patients. Psychiatry J. 2013;2013:691050. doi:10.1155/2013/691050. [PubMed:24233448]

21. Jargin S. Renal Biopsy for Research: An Overview of Russian Experience. J Interdisciplinary Histopathol. 2014:1. doi: 10.5455| jihp.20140312020838.

22. Jargin SV. Limited access to the international medical literature in Russia. Wien Med Wochenschr. [in German] 2012;162(11-12):272-5. doi:10.1007/s10354-012-0111-2. [PubMed: 22688620]

23. Jargin SV. Invasive procedures with questionable indications and possible placebo effects. Arch Clin Exp Surg. 2015;4(4):215-221. doi:10.5455/aces.20140810014858. 